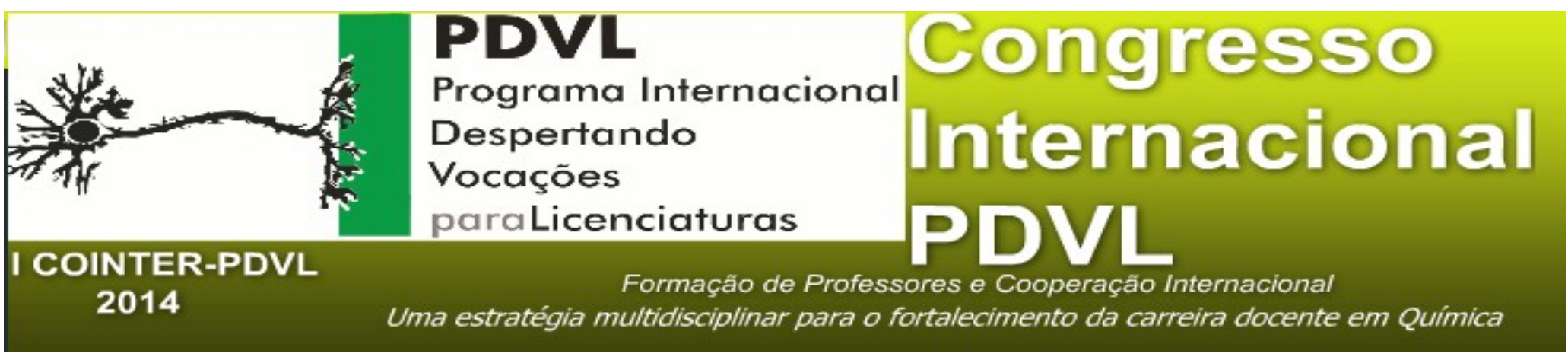

\title{
EDUCAÇÃO AMBIENTAL A PARTIR DO LIXO: PROJETO INTERDISCIPLINAR DESENVOLVIDO ATRAVÉS DO PIBID
}

\author{
Apresentação: Comunicação Oral \\ Mayrane Carla Marques do Nascimento; Kleyfton Soares da Silva ${ }^{2}$; Alan John Duarte de \\ Freitas $^{3}$; Johnnatan Duarte de Freitas ${ }^{4}$
}

\begin{abstract}
Resumo
Este trabalho tem por objetivo descrever a realização de um projeto interdisciplinar a partir da importância da reciclagem do lixo no ambiente escolar. O projeto foi aplicado em quatro etapas roda de conversa com os alunos; mobilização e limpeza da escola; realização de oficinas e discussões; exposição. Foi desenvolvido numa escola pública de Maceió/AL por discentes de Curso de Licenciatura em Química por meio do Programa Institucional de Bolsas de Iniciação à Docência (PIBID). Buscou-se aprimorar o processo de aprendizagem dos alunos da educação básica a partir de ações de conscientização e aplicação de conhecimentos em química e matemática com o objetivo de incentivar a reciclagem e redução do lixo produzido na escola. Como resultados, os alunos mostraram compromisso e dinamismo durante a culminância do projeto, além disso, aplicaram suas experiências cotidianas através de trabalho conjunto e consciente, a favor da melhoria do ambiente escolar.
\end{abstract}

1Licenciatura em Química/Instituto Federal de Alagoas (IFAL) / Programa Institucional de Bolsa de Iniciação à Docência - PIBID / mayrane.carla@hotmail.com ²Licenciatura em Química/ Instituto Federal de Alagoas (IFAL) / Programa Institucional de Bolsas de Iniciação à Docência/kley.soares@hotmail.com ºutor em Química / Instituto Federal de Alagoas (IFAL) / Programa de Extensão Internacional Despertando Vocações para as Licenciaturas - PDVL / Programa Institucional de Bolsa de Iniciação à Docência - PIBID / ajdfifal@gmail.com

${ }^{4}$ Doutor em Química / Instituto Federal de Alagoas (IFAL) / Programa de Extensão Internacional Despertando Vocações para as Licenciaturas - PDVL / Programa Institucional de Bolsa de Iniciação à Docência - PIBID/ johnnatan.duarte@ifal.edu.br 
Palavras-Chave: Educação Ambiental. Interdisciplinaridade. Lixo

\section{Introdução}

Questões relacionadas com o meio ambiente têm sido amplamente discutidas e as consequências do falho gerenciamento humano tem preocupado a sociedade. Nesse sentido, é importante que educadores de uma forma geral abordem assuntos que envolvam o meio ambiente nas escolas, levando em consideração que, conforme GOTUZZO (2011), a Educação Ambiental (EA) é caracterizada por um processo que passa a sensibilizar e a estimular os indivíduos a uma mudança comportamental diante do ambiente no qual estão inseridos.

Para o estudo da educação ambiental é importante que a escola trabalhe de maneira transversal e interdisciplinar (BRASIL, 1997). Pois, são muitos os conceitos que podem ser abordados através dessa temática.

No espaço escolar é importante que todos os professores tomem consciência da necessidade de integrar o conteúdo de educação ambiental aos demais vistos em sala de aula, pois, sabemos que muitos profissionais não dão ênfase a temáticas como esta, dirigindo-se sempre ao ensino especifico de suas áreas de atuação.

O Lixo, é um dos conceitos importantes que deve ser abordado em sala de aula, visto ser tão presente no dia a dia. Este não é só realidade das ruas, casas, empresas, dentre outras instituições, é também, uma problemática de muitas escolas que não possuem um quadro adequado de funcionários destinados à limpeza, bem como não dispõe de alunos e funcionários verdadeiramente conscientes.

Refletindo-se acerca da importância da educação ambiental e da problemática do lixo, um projeto interdisciplinar foi desenvolvido numa escola pública do município de Maceió/AL, com o objetivo de aprimorar os conhecimentos dos alunos a partir de ações ambientais que pudessem trabalhar a favor do ambiente escolar, pois a questão do lixo foi um negativo aspecto observado na escola, visto que esta faz parte do grupo de escolas que não possuem um quadro adequado de funcionários para limpeza. As ações trabalhadas discorreram de maneira interdisciplinar através do uso de conceitos químicos e matemáticos na temática educação ambiental, em específico problema com o lixo da escola. 


\section{Fundamentação Teórica}

No dia a dia, as pessoas estão diariamente descartando resíduos e estes resíduos denominados lixos são restos de materiais produzidos em todos os lugares e em todos os momentos. Nas escolas este processo não é diferente, ele ocorre diariamente e em grande quantidade.

De acordo com Oliveira (2006), o lixo constitui-se de resíduos da atividade humana em sociedade e também de qualquer material que seu proprietário ou produtor não considere mais com valor suficiente para conservá-lo.

Quando se fala sobre lixo, trata-se de questões sociais, ambientais e econômicas, e segundo Calderoni (2003, p. 123):

Sob o ponto de vista econômico, resíduo ou lixo é todo material que uma dada sociedade ou agrupamento humano desperdiça. Isso pode decorrer de várias razões como sejam, por exemplo, problemas ligados à disponibilidade de informação ou de meios para realizar o aproveitamento do produto descartado, inclusive da falta de desenvolvimento de um mercado para produtos recicláveis.

A fala de Calderoni é importantíssima em se tratando do lixo no ambiente escolar, pois o que se observa em muitas escolas são grandes quantidades de resíduos sendo despejados sem qualquer tipo de separação, por conta da falta de discernimento e incentivos para reaproveita-los.

É justamente nesse momento que o papel da escola se torna fundamental, tendo em vista o objetivo de formar alunos críticos e reflexivos em torno de questões tão importantes. Nesse sentido, a simples pergunta sobre o que fazer com o lixo que é gerado por todos no ambiente escolar pode ser palco de grandes reflexões e ações práticas.

Nos espaços escolares, principalmente nas salas de aula, os resíduos são produzidos em grande escala, na maioria das vezes desnecessariamente. É importante que alunos, professores, gestores e demais funcionários da escola compreendam que os resíduos podem ser coletados para reciclagem industrial ou até mesmo para serem reaproveitados para outras finalidades.

Sabe-se, que nos dias atuais muitos trabalhos estão sendo realizados objetivando a redução 
do lixo gerado, como exemplo o trabalho de reciclagem e do sistema de coleta seletiva. Mas a preocupação dos governantes e da sociedade acerca da recuperação dos materiais recicláveis é mínima.

Logo, no ambiente escolar, para que o lixo venha a ser reduzido e reaproveitado é necessário que sejam realizados trabalhos com os alunos, assim como, com demais funcionários para que todos numa ação conjunta possam desenvolver o senso crítico e reflexivo a favor da conservação do ambiente escolar.

\section{A importância do PIBID como mediador de projetos}

Desde a implementação até os dias atuais, o Programa Institucional de Bolsas de Iniciação à Docência (PIBID) tem motivado estudantes de cursos de licenciaturas para o seu reconhecimento como futuros profissionais da educação. O programa abre as portas das escolas públicas de educação básica para que o licenciando, com o auxílio de supervisores, passe a vivenciar desde cedo as ações das escolas em termos de gestão e metodologias de ensino. Assim, o programa tem oportunizado a implementação de novas metodologias e técnicas de ensino através da intervenção dos licenciandos. Dessa forma, o PIBID é um importante mediador de práticas diferenciadas no processo de ensino e aprendizagem no Brasil.

De acordo com a CAPES - instituição que gerencia o PIBID - o programa tem como um dos objetivos inserir os licenciandos no cotidiano de escolas da rede pública de educação, proporcionando-lhes oportunidades de criação e participação em experiências metodológicas, tecnológicas e práticas docentes de caráter inovador e interdisciplinar que busquem a superação de problemas identificados no processo de ensino e aprendizagem.

A partir desta ideia, os licenciandos que já foram inseridos na educação básica através do programa, estão realizando trabalhos diferenciados de forma prática e dinâmica.

A pedagogia de projetos é um das propostas metodológicas que é custeada pelo programa. Quando são necessários recursos financeiros para realização concreta dos mesmos, os discentes que são bolsistas do PIBID dispõem dos recursos que a CAPES libera para a realização dessa atividade, desde que esta esteja devidamente elaborada, e que vise trazer resultados relevantes para a comunidade.

Segundo PRADO et al (2005), a pedagogia de projetos deve permitir que o aluno aprenda- 
fazendo e reconheça a própria autoria naquilo que produz por meio de questões de investigação que lhe impulsionam a contextualizar conceitos já conhecidos e descobrir outros que emergem durante o desenvolvimento do projeto. Nesta situação de aprendizagem, o aluno precisa selecionar informações significativas, tomar decisões, trabalhar em grupo, gerenciar confronto de ideias, enfim desenvolver competências interpessoais para aprender de forma colaborativa com seus pares.

Por isso é importante que se compreenda a importância do projeto, pois é ele a base das mudanças que já foram implantadas em várias escolas e continuam sendo trabalhadas em prol de uma educação de mais qualidade que não forme apenas alunos que aprendem fórmulas e conceitos, mas sim alunos críticos que conseguem relacionar os conhecimentos adquiridos na escola com o cotidiano. E nos reforça, Silva, et al (2008) que os projetos sugerem romper com as formas tradicionais de organização curricular, oferecendo uma alternativa à maneira rígida e quase intransponível de como as disciplinas e os conteúdos estão presentes nos livros didáticos e no planejamento dos professores.

\section{Metodologia}

A metodologia utilizada foi o desenvolvimento de atividades baseadas na pedagogia de projetos. O projeto foi desenvolvido por discentes do Curso de Licenciatura em Química do Instituto Federal de Alagoas, Campus Maceió, na qual teve como público alvo alunos do ensino fundamental e médio de uma escola estadual de Maceió-AL.

Este foi dividido em quatro etapas como mostra a tabela abaixo:

\begin{tabular}{|c|c|c|c|}
\hline ATIVIDADES & $\begin{array}{c}\text { DATA DE } \\
\text { REALIZAÇÃ } \\
\text { O }\end{array}$ & PARTICIPANTES & RESPONSÁVEIS \\
\hline Rodas de conversa & $\begin{array}{c}09 \text { a } \\
13 / 09 / 2013\end{array}$ & $\begin{array}{c}\text { Bolsistas do PIBID e } \\
\text { Alunos }\end{array}$ & $\begin{array}{c}\text { Bolsistas do PIBID } \\
\text { (Química) }\end{array}$ \\
\hline Mutirão de limpeza & $21 / 09 / 2013$ & $\begin{array}{c}\text { Todos que compõem a a } \\
\text { escola }\end{array}$ & $\begin{array}{c}\text { Bolsistas do PIBID, } \\
\text { Professores e } \\
\text { gestores }\end{array}$ \\
\hline $\begin{array}{c}\text { Aplicação do vídeo } \\
\text { e realização das } \\
\text { oficinas }\end{array}$ & $19 / 10 / 2013$ & $\begin{array}{c}\text { Alunos, Bolsistas do } \\
\text { PIBID, colaboradores }\end{array}$ & $\begin{array}{c}\text { Bolsistas do PIBID } \\
\text { (Qúmica) e } \\
\text { colaboradores }\end{array}$ \\
\hline Culminância & $23 / 11 / 2013$ & Alunos & $\begin{array}{c}\text { Bolsistas do PIBID } \\
\text { (Química) e } \\
\text { Supervisor }\end{array}$ \\
\hline
\end{tabular}


Tabela 1: ciclo de atividades

De acordo com Coelho (2007), a roda de conversa cria espaços de diálogo na qual as pessoas podem escutar os outros e a si mesmos, através de trocas de experiências. Nesse sentido, foram realizadas discussões sobre os impactos causados pelo lixo no ambiente escolar para que os alunos pudessem contribuir com seus conhecimentos prévio. Dessa forma, foi um momento informativo acerca do que seria realizado nos outros momentos de atividades.

A segunda etapa consistiu da mobilização em que todos os alunos e demais funcionários que compõe a escola estiveram presentes para a realização de uma limpeza conjunta de todo o compartimento escolar, realizada em um dos sábados letivos do calendário escolar.

A terceira etapa foi realizada no auditório da escola e contou com a presença dos alunos, bolsistas do PIBID e colaboradores de outras instituições que trabalharam com oficinas que trataram do lixo reciclável. Inicialmente os alunos assistiram ao vídeo, foi discutido acerca da temática e depois, estes se dividiram em grupos para realização das oficinas: caixinhas de papel, portas-treco de garrafas pet, construção de horta orgânica.

A culminância foi a etapa do projeto na qual os alunos se dividiram em dois grupos por turma, para apresentar as inúmeras questões referentes ao lixo. As apresentações ficaram a critério dos alunos como por exemplo: apresentações em forma cartazes, apresentação em slides com o uso de projetor, paródias, dentre outras.

\section{Resultados e Discussões}

\section{Rodas de conversas}

Nos momentos de rodas de conversas, os conhecimentos foram disseminados de maneira prazerosa, pois se conseguiu discutir sobre o tema do projeto de forma dinâmica.

Os alunos fizeram uma série de perguntas acerca dos conceitos de lixo, quais os tipos de lixo existentes, como eles são reaproveitados, dentre outras perguntas. Os bolsistas responderam muitas das indagações, no entanto deixaram por conta dos alunos, pesquisarem também questões especificas sobre o projeto.

Foi discutida a importância de se manter o ambiente escolar limpo e organizado, bem como 
da necessidade de serem desenvolvidas atividades como os projetos para conscientizar a comunidade escolar de maneira significativa.

Conseguiu-se despertar um olhar crítico e reflexivo por parte dos alunos em relação a questões ambientais, assim como foi possível aguçar a curiosidade destes para pesquisar e realizar ações que beneficiem a sociedade em geral e principalmente a comunidade escolar participante do projeto.

\section{Mutirão de Limpeza}

Na etapa do mutirão todos os alunos e demais funcionários que compõem a escola, juntamente com os bolsistas do PIBID se juntaram para organizá-la.

Os resultados obtidos foram de extrema relevância, pois uma das maiores problemáticas da escola é a falta de limpeza, principalmente em alguns compartimentos como os laboratórios, que antes do PIBID ser inserido quase nunca era utilizado e limpo.

Como se tratou de uma atividade que necessitava de trabalho manual com uso de vassouras, rodos, e materiais de limpeza, a presença dos alunos não era obrigatória, no entanto, conseguiu-se um número elevado de alunos e funcionários para realização da mesma. A figura 1 mostra alguns alunos participando da arrumação e limpeza da escola.

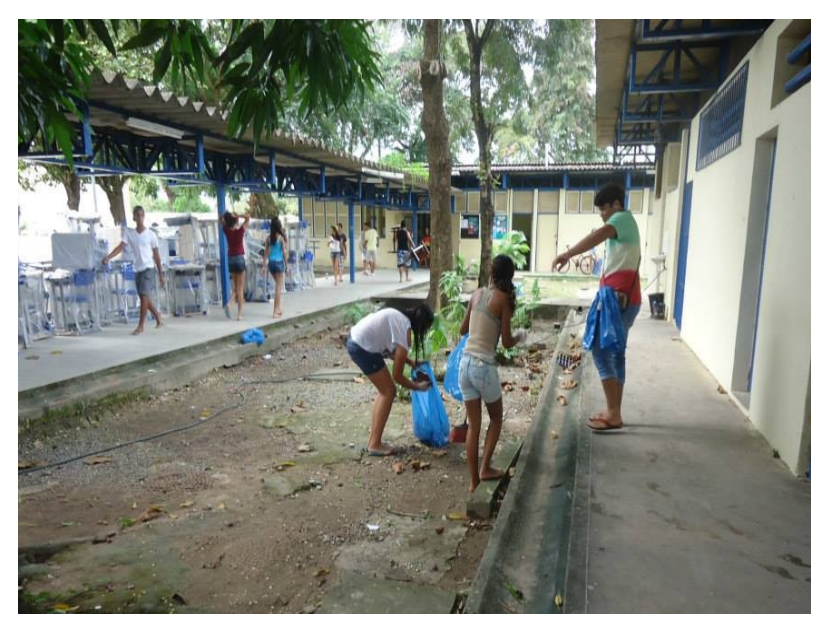

Figura 1 - Momento da limpeza e arrumação da escola. Fonte: Própria

Com o auxílio dos alunos, todas as salas de aulas foram lavadas. As salas de coordenação e direção ficaram por conta dos gestores da escola. A limpeza dos laboratórios ficou por conta dos bolsistas do PIBID. Os demais compartimentos por conta dos funcionários da área de apoio. 
Ao fim da ação, a escola ficou como todos almejaram - limpa e organizada. No entanto, o que de mais importante conseguiu-se conquistar nesse dia, foi a formação de alunos conscientes e cidadãos que se preocupam com a escola e com as condições que a mesma se encontra.

\section{Aplicação do vídeo sobre lixão de Maceió, discussões e oficinas.}

Nessa etapa, os momentos de satisfação foram vários, pois, inicialmente foi realizada uma pesquisa sobre cooperativas que trabalham com reciclagem, e chegou-se a cooperativa "COPVILA" situada no bairro do São Jorge no município de Maceió-AL.

Foi realizada uma visita à cooperativa onde foi possível compreender a importância da reciclagem a partir dos processos de coleta da instituição. Ao termino da visita, foi doado um DVD sobre o antigo lixão de Maceió e posteriormente aplicado com os alunos.

A aplicação do vídeo foi um momento de bastante seriedade enquanto atividade trabalhada durante o projeto, pois, apesar de ser uma realidade desumana e tão comentada pela sociedade alagoana, todas as pessoas participantes da exibição do vídeo ficaram chocadas em saber que anos atrás existiam tantas pessoas dependendo do lixão para sobreviverem. As discussões posteriores à exibição do vídeo foram de bastante relevância, pois os alunos deram seus depoimentos acerca do que acharam do vídeo e principalmente, se emocionaram com as cenas e depoimentos que ouviram.

Assim como o vídeo, as oficinas trabalhadas também proporcionaram resultados bastante significativos. Os alunos participaram com muita curiosidade e contentamento no processo de construção da horta orgânica, bem como dos objetos feitos de materiais recicláveis. Estes foram muito bem orientados pelos colaboradores.

No momento das oficinas os alunos puderam averiguar o quanto o papel, garrafa pet, papelão, pedaço de espuma, entre outros materiais podem ser reaproveitados, pois estes construíram, por exemplo: caixinhas de presente a partir do papel e os portas-treco com uso de garrafas pet.

Ao término das oficinas, os colaboradores ainda deram dicas aos alunos de como produzir outros objetos a partir de materiais recicláveis em suas residências. Como por exemplo, embalagens para presente também feitas de papel, assim como árvores de natal com uso de garrafa pet e outros materiais para decoração. 
Ao fim desta etapa, todos os alunos saíram bastante satisfeitos por terem tido a oportunidade de serem informados de questões tão presentes no dia a dia e que muitas vezes não são comentados e trabalhados no ambiente escolar.

\section{Culminância do projeto}

O dia da culminância foi o momento em que os alunos participantes realizaram diversas apresentações acerca de tudo que eles puderam compreender durante as outras atividades desenvolvidas no projeto, juntamente com o que eles pesquisaram nos momentos fora de sala de aula. Este foi surpreendente para bolsistas do PIBID, professores e gestores da escola.

Todas as turmas participantes dividiram-se em dois grupos cada. As apresentações foram realizadas em diferentes formas. Muitas apresentaram em forma de cartazes, outras em forma de dança e paródias, mas todas com um nível elevadíssimo de conhecimentos adquiridos.

Percebeu-se que muitas turmas optaram em apresentar em forma de cartazes, de maneira bem convencional, estas apresentações foram bastante significativas, pois estes alunos expuseram de maneira muito clara o conteúdo proposto como, por exemplo: explicar o lixo orgânico. Mas, além da explicação eles se preocuparam em levar o tipo de lixo como demonstração prática e visual do conteúdo.

As turmas de oitavo e nono ano do ensino fundamental, assim como as dos primeiros anos do ensino médio, apresentaram em grande maioria apenas na forma de cartazes, com exceção de um grupo do $9^{\circ}$ ano e um do $1^{\circ}$ que prepararam e cantaram paródias como complemento das apresentações. A figura 2 mostra alguns dos grupos referidos que apresentaram paródias. 


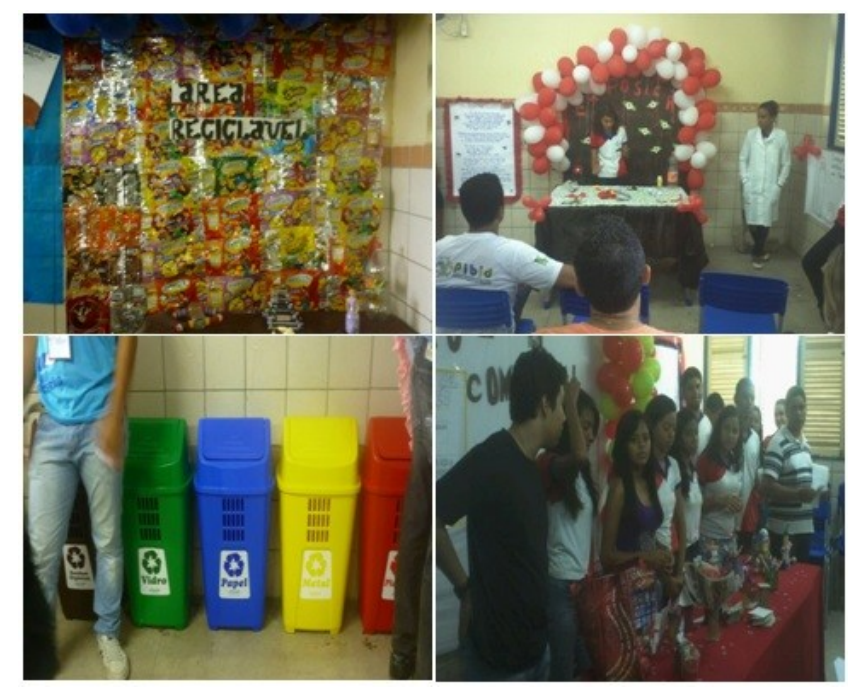

Figura 2 - Apresentação de trabalhos por alunos. Fonte: Própria

As turmas de segundos e terceiros anos do ensino médio diversificaram um pouco mais, pois foram as turmas que confeccionaram camisas, bem como prepararam como complementos para as apresentações: danças e espaços cinematográficos referentes ao tema proposto. A Figura 3 apresenta imagens das turmas de $2^{\circ}$ e $3^{\circ}$ anos no dia da culminância do projeto.
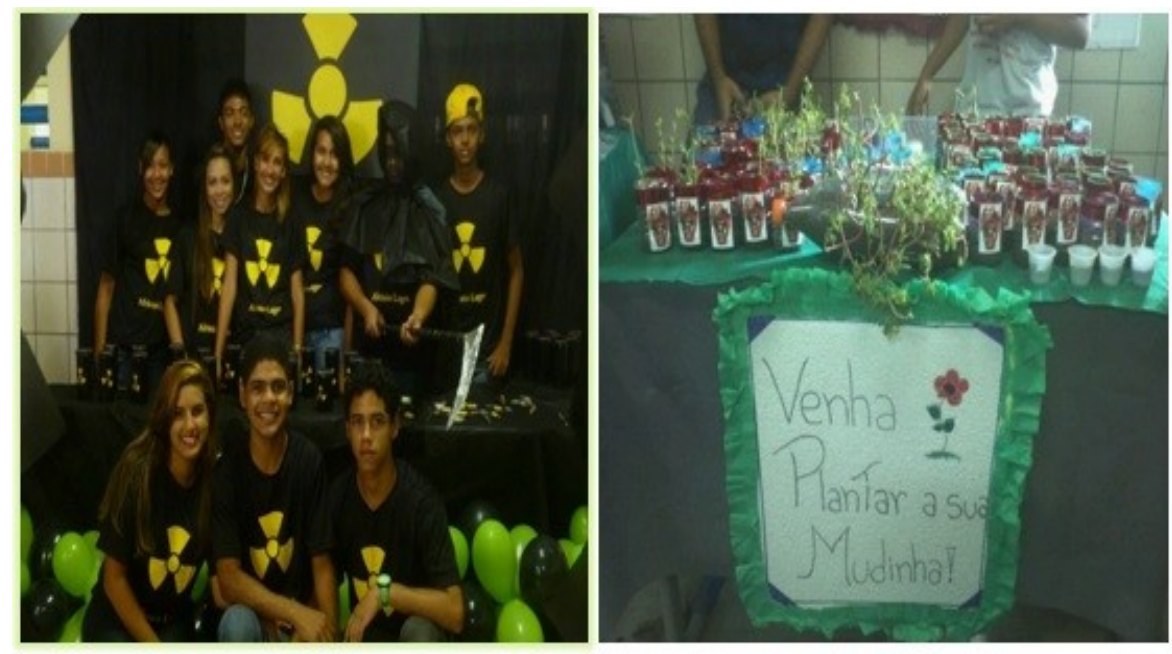

Figura 3 - Apresentação de trabalhos por alunos. Fonte: própria

Durante as apresentações, os alunos foram indagados pelos bolsistas do PIBD acerca de questões especificas sobre o tema de cada grupo, assim como, acerca da importância de projetos de conscientização na escola. Muitos dos alunos responderam que "os projetos na escola são muito importantes, pois, para entender os impactos ambientais causados pelo lixo no ambiente escolar, eles precisavam compreender primeiramente sobre os tipos de lixos existentes na natureza e como devemos nos comportar frente a produção e despejo dos mesmos nos locais que convivemos 
diariamente”.

Conseguiu-se formar alunos conscientes, que se preocuparam até em utilizar o lixo orgânico produzido pela escola para servir de adubo para produção de hortas. Assim como o uso das garrafas pet também despejadas na escola como material reciclável para construção de vários brinquedos.

Os alunos compreenderam ainda, a maneira como os conteúdos químicos e matemáticos estão intrinsicamente relacionados aos tipos de lixo existentes. Muitos dos grupos preocuparam-se em confeccionar moléculas orgânicas com o objetivo de mostrar as substancias presentes na composição de cada resíduo, assim como, fizeram uso de gráficos para mostrar os percentuais de lixo produzidos ao ano.

Enfim, averiguou-se que é necessária realização de projetos como este, e que estas discussões devem ocorrer periodicamente para que as questões ambientais não sejam esquecidas.

\section{Conclusões}

O desenvolvimento do projeto possibilitou a reflexão acerca da importância de se trabalhar temáticas e propostas metodológicas diferenciadas no processo de ensino e aprendizagem como forma de aprimorá-lo.

Averiguou-se que o projeto seja interdisciplinar ou não, é uma das maneiras de proporcionar disseminação de conhecimento de forma dinamizada, através de vários trabalhos e ações que são realizadas para o benefício da escola e sociedade. Percebeu-se ainda, que os demais funcionários que compõe a escola também foram conscientizados em relação à importância do lixo e seu uso enquanto material reciclável.

Por fim, devemos refletir que o espaço escolar é um ambiente que deve estar sempre limpo para ser um espaço de aprendizagem agradável a todos.

\section{Referências}

1. CALDERONI, Sabetai. Os bilhões perdidos no lixo. São Paulo: Humanitas, $4^{\mathrm{a}}$ ed., 
2003.

2. COELHO, D. M. (2007). Intervenção em grupo: construindo rodas de conversa. Anais do XIV Encontro Nacional da Abrapso, Rio de Janeiro, RJ, Brasil.

3. GOTUZZO, Filipi Gonçalves. Diagnóstico sobre Educação Ambiental nas escolas municipais de Pelotas, Rio Grande do Sul. 2011. 44f. Monografia (Conclusão de curso). Ciências Biológicas. Instituto de Biologia. Universidade Federal de Pelotas.

4. OLIVEIRA, Nilza Aparecida da Silva. A percepção dos resíduos sólidos (lixo) de origem domiciliar, no Bairro Cajuru-Curitiba-PR: um olhar reflexivo a partir da educação ambiental. Dissertação (Mestrado), 2006. 174 f. Disponível em: <http://dspace.c3sl.ufpr.br/dspace/bitstream/1884/4122/1/nilza.pdf/>. Acesso em: 01. Outubro. 2014.

5. PRADO, Maria Elisabette Brisola Brito. Pedagogia de projetos: fundamentos e implicações. In: ALMEIDA, Maria Elizabeth Bianconcini de; MORAN, José Manuel (Org.). Integração das tecnologias na educação. Brasília: Ministério da Educação/SEED/TV /Escola/Salto para o Futuro, 2005. cap. 1, artigo 1.1, p. 12-17. Disponível em: $<$ http://www.tvebrasil.com.br/salto>. Acesso em: 05 de Jan.2014.

6. $\quad$ PIBID. <Disponível em: http://www.capes.gov.br/educacao-basica/capespibid > Acesso em: 20 outubro de 2014.

7. SILVA, Petronildo Bezerra. et al. A Pedagogia de Projetos no Ensino de Química - O Caminho das Águas na Região Metropolitana do Recife: dos Mananciais ao Reaproveitamento dos Esgotos. Química Nova na Escola. no 29. p. 14- 19. Agosto de 2008. 